\title{
Rapid detection of group B streptococcus and Escherichia coli in amniotic fluid using real-time fluorescent PCR
}

\author{
Michele Straka ${ }^{1}$, Wifred Dela Cruz ${ }^{2}$, Camille Blackmon ${ }^{2}$, Oswald Johnson ${ }^{2}$, \\ Sara Stassen ${ }^{2}$, David Streitman ${ }^{1}$, Stephen Golden ${ }^{2}$, David Stamilio ${ }^{3}$ \\ ${ }^{1}$ Department of Obstetrics and Gynecology, David Grant Medical Center, Travis AFB, CA, USA \\ ${ }^{2}$ Clinical Investigation Facility, David Grant Medical Center, Travis AFB, CA, USA \\ ${ }^{3}$ Department of Obstetrics and Gynecology, University of Pennsylvania Medical Center, Philadelphia, PA, USA
}

\begin{abstract}
Objective: To establish reliability and validity of real-time fluorescent PCR for early detection of bacterial invasion of the amniotic cavity.

Methods: Amniotic fluid samples from 40 patients undergoing mid-trimester genetic amniocentesis were incubated for $6 \mathrm{~h}$ at $37^{\circ} \mathrm{C}$ and were cultured on media specific for group B streptococcus (GBS) and $E$. coli. Concurrently, samples were analyzed with real-time fluorescent PCR (Roche LightCycler) using DNA primers and probes designed to detect the CAMP factor encoding $c f b$ gene and uidA gene of GBS and $E$. coli, respectively. For positive control and to simulate amniotic fluid colonization, $104 \mathrm{cfu} / \mathrm{ml}$ of GBS and $E$. coli were inoculated on sterile amniotic fluid and incubated for $6 \mathrm{~h}$. Bacterial genomic DNA for the two organisms was extracted and purified via the two-step precipitation method using a commercial kit. The real-time PCR assays were also tested against 25 non-GBS and non-E. coli bacterial species. The lower limit of detection for each pathogen was established using serial dilution of bacterial genomic DNA.

Results: All patient samples were negative for evidence of GBS and $E$. coli with both culture and real-time PCR methods. Amniotic fluid samples inoculated with GBS and E. coli were positive with real-time PCR whereas the 25 bacterial species other than GBS or E. coli tested negative with the assay. Average total sample processing time including the pre-enrichment step was $7 \mathrm{~h} 40 \mathrm{~min}$. The average cost for DNA extraction and PCR testing was $\$ 8.50$ per test.

Conclusion: Real-time fluorescent PCR is a valid and reliable method for detection of specific pathogens in amniotic fluid. This technique is sensitive for low inoculation levels. Real-time fluorescent PCR has potential to impact clinical management as a rapid, reliable detection method for GBS and E. coli in chorioamnionitis.
\end{abstract}

Key words: ReAL-TIME FLUORESCENT PCR; E. COLI; GBS

\section{INTRODUCTION}

Preterm birth occurs in approximately $11 \%$ of all pregnancies. Preterm labor may be initiated by infection in $33 \%$ of cases with intact membranes and in $40 \%$ with preterm premature rupture of membranes (pPROM). Early preterm birth $(<32$ weeks gestation) has the strongest association with infection ${ }^{1}$. Neonatal sepsis occurs more commonly with early preterm birth, accounting for a large portion of perinatal morbidity and mortality. Pathogens that have been isolated from amniotic fluid in these cases include Ureaplasm urealyticum, Mycoplasm hominis, fusobacterium species, prevo-

Correspondence to: Michele Straka, David Grant Medical Center, 101 Bodin Circle, Travis AFB, CA 94535, USA.

E-mail: michelle.straka@60mdg.travis.af.mil

(C) 2004 Parthenon Publishing. A member of the Taylor \& Francis Group Ltd.

DOI: 10.1080/I0647440400020679 
tella species, gardnarella vaginalis, streptococcus agalactiae, anaerobic streptococci and Escherichia $\operatorname{coli}^{2,3}$. In the pathogenesis of intra-amniotic infection, or chorioamnionitis, it appears that vaginal organisms overcome available cervical barrier and immunity factors and penetrate the chorioamnion to enter the amniotic fluid. Ultimately, some fetuses become infected ${ }^{4}$.

Identifying the gravid patient destined to deliver prematurely because of ascending genital tract infection is difficult. Many patients remain asymptomatic until they present in preterm labor, and most of them do not show signs of chorioamnionitis. Even patients with pPROM often lack clinical evidence of infection upon presentation. Current clinical management of preterm labor and pPROM does not universally include routine amniocentesis because there are no rapid, reliable diagnostic tests for intraamniotic infection and because infection rates vary among clinical populations. Amniotic fluid culture takes 48 to $72 \mathrm{~h}$, and may lack the sensitivity needed to reliably identify infection at a stage when intervention could alter outcome. Amniotic fluid glucose, Gram stain and leukocyte esterase assays provide rapid results, but have poor predictive value for infection-mediated preterm labor, and even less for identifying the neonate destined to develop sepsis. Ideally, accurate identification of bacterial invasion of the amniotic cavity might allow expedient and targeted management of infection-mediated preterm labor.

PCR is used to identify genetic material of pathogenic microorganisms by amplification, with highly specific and sensitive results, and has been shown to detect bacteria in amniotic fluid at a higher rate than standard microbial cultures ${ }^{3,5,6}$. Unfortunately, PCR requires additional laboratory techniques to detect the amplified genomic signal, taking up to 1 day to obtain results. Realtime PCR employs the same biomolecular techniques that provide the sensitivity and specificity of traditional PCR, but detection of the pathogenic microorganism occurs during the amplification process, shortening the time to detection of pathogen.

The objective of our study was to develop a valid, reliable test for detection of GBS and E. coli in amniotic fluid.

\section{MATERIALS AND METHODS}

This study was initiated after approval by the Institutional Review Board at David Grant USAF Medical Center. For genetic analysis, 40 amniotic fluid samples were obtained from women undergoing mid-trimester amniocentesis. To test amniotic fluid samples for GBS and E.coli infection by standard culture and conventional and real-time PCR, $2 \mathrm{ml}$ of each sample were incubated for $6 \mathrm{~h}$ at $37 \mathrm{C}$. Samples were frozen, stored at $-70 \mathrm{C}$ and batched for later analysis. An aliquot of each sample was cultured according to CDC recommendations for detection of GBS and E.coli. A second aliquot was processed for traditional and realtime fluorescent PCR using a Roche LightCycler. Bacterial DNA was extracted using the Gentra Systems Puregene DNA isolation kit, modified by the addition of a second precipitation step.

\section{Pathogen genomic targets}

The real-time PCR probe for GBS targeted the $c f b$ gene encoding the Christie-Atkins-MunchPetersen (CAMP) factor ${ }^{7}$. Hybridization probes designed to anneal to an internal sequence of the 153 base pair (bp) amplicon were used. The E. coli target for the assay consists of a $186 \mathrm{bp}$ sequence of the uid $A$ gene encoding the $\beta$-glucoronidase protein. GBS or E. coli was detected in each sample in triplicate using the Hybridization (GBS) or Taqman (E.coli) probe systems in the LightCycler.

\section{Specificity of assays}

To assess the specificity of the Hybridization and Taqman probe assays, a battery of 25 non-GBS and non- $E$ coli bacterial strains were grown on blood agar plates, and $40 \mu \mathrm{l}$ of a $104 \mathrm{cfu} / \mathrm{ml}$ bacterial suspension of each strain were added to $500 \mu \mathrm{l}$ amniotic fluid sample and incubated for $6 \mathrm{~h}$ at $37 \mathrm{C}$. The sample was then tested for the presence of GBS and E coli target DNA on the LightCycler, in duplicate. 


\section{Spiked samples}

Streptococcus agalactiae (ATCC 12386) and E. coli (ATCC 35218) were grown in pure culture on blood agar plates and diluted to $104 \mathrm{cfu} / \mathrm{ml}$. Then $40 \mu \mathrm{l}$ (25 cfu total) of each of the bacterial suspensions were added to 500 ?? $\mu v$ ? aliquots of amniotic fluid, incubated at $37 \mathrm{C}$ for $6 \mathrm{~h}$ and stored at $-80 \mathrm{C}$ until analyzed. PCR-grade distilled, de-ionized water was used as negative control for both traditional PCR and real-time PCR. The dilute bacterial suspensions served as the positive control for traditional and real-time PCR.

\section{Limit of detection}

To determine the lower limit of detection of the assays, pure genomic DNA extracted from GBS or E. coli cultured on sheep blood agar was obtained using the Gentra Puregene Isolation kit with the modification noted above. RNAse and proteinase $\mathrm{K}$ treatment steps after DNA isolation were added to remove contaminating proteins and RNA. The concentration of DNA was calculated by measuring absorbance at 260 and $280 \mathrm{~nm}$. DNA concentration was adjusted to $1 \mu M$ and serial dilution of DNA in Tris buffer was performed. GBS or E. coli was detected from each concentration in triplicate using the Hybridization (GBS) or Taqman (E. coli) probe systems in the LightCycler.

\section{RESULTS}

As was anticipated on the basis of the clinical histories, none of the 40 native amniotic fluid samples had evidence of E.coli or GBS by culture, conventional PCR or real-time PCR. All amniotic fluid samples inoculated with GBS or E. coli were uniformly positive by real-time PCR (Figure 1). PCR product results were confirmed by gel electrophoresis (Figure 2). Therefore, in our laboratory the real-time PCR system was 100\% sensitive and specific for detecting GBS and E. coli in amniotic fluid. In the limit of detection studies we were able to consistently detect 25 genomic copies (50 cfu/ml) (Figure 3). The average time to complete the real-time PCR
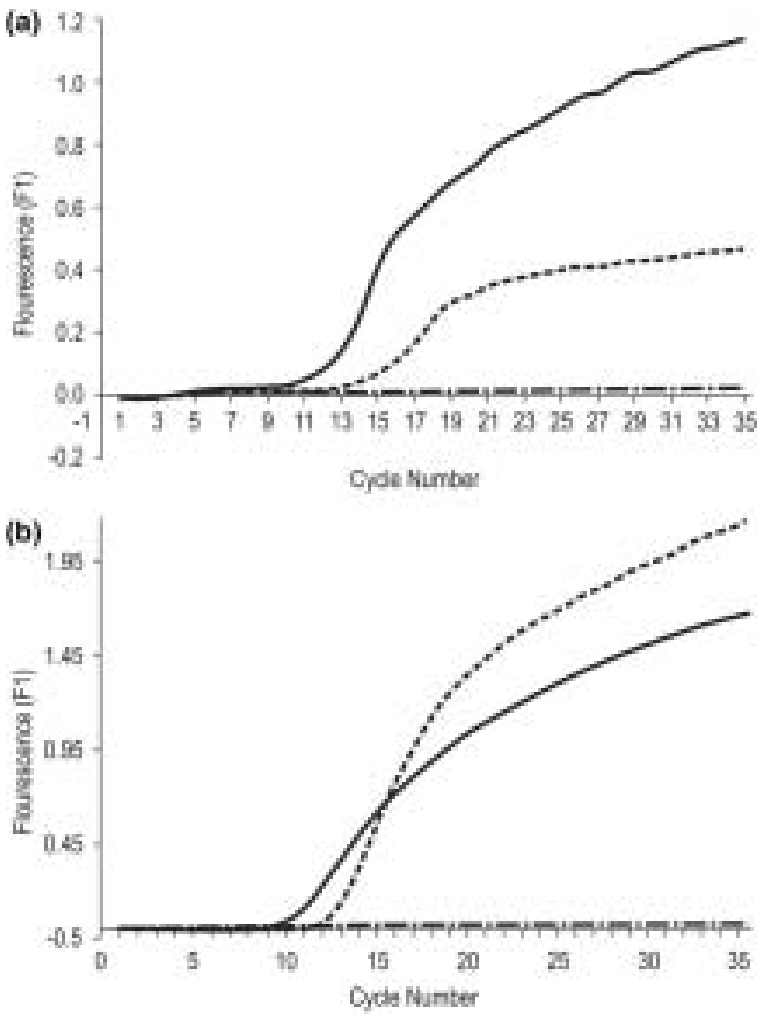

Figure I LightCycler ${ }^{T M}$ PCR graph showing hybridization probe (GBS) and Taqman (E. coli) results, demonstrating $(A)$ increased fluorescence for group $B$ streptococci (solid) positive controls (dash), and (B) E. coli (solid) positive controls (dash). No fluorescence was observed for the negative control (PCR grade water) and patients' samples negative for GBS or $E$. coli (broken line)

testing was $1 \mathrm{~h} 40 \mathrm{~min}$ after the 6-h incubation period study protocol had elapsed.

\section{DISCUSSION}

We have shown that real-time PCR is a sensitive $(100 \%)$ and rapid method for detecting pathogens in amniotic fluid that are commonly involved in the pathogenesis of preterm labor and adverse neonatal outcome. We consistently detected artificially created infected amniotic fluid samples and consistently detected greater than $50 \mathrm{cfu} / \mathrm{ml}$ of pathogen. We also proved that the real-time PCR system is highly specific (100\%), by showing that the probes tested did not detect alternative bacterial species or produce false-positive results in control samples devoid of bacteria. Real-time PCR proved to be valid and reliable when 
A

$\begin{array}{lllllllllllllllllllll}1 & 2 & 3 & 4 & 5 & 6 & 7 & 8 & 9 & 10 & 11 & 12 & 13 & 14 & 15 & 16 & 17 & 18 & 19 & 20 & 21\end{array}$
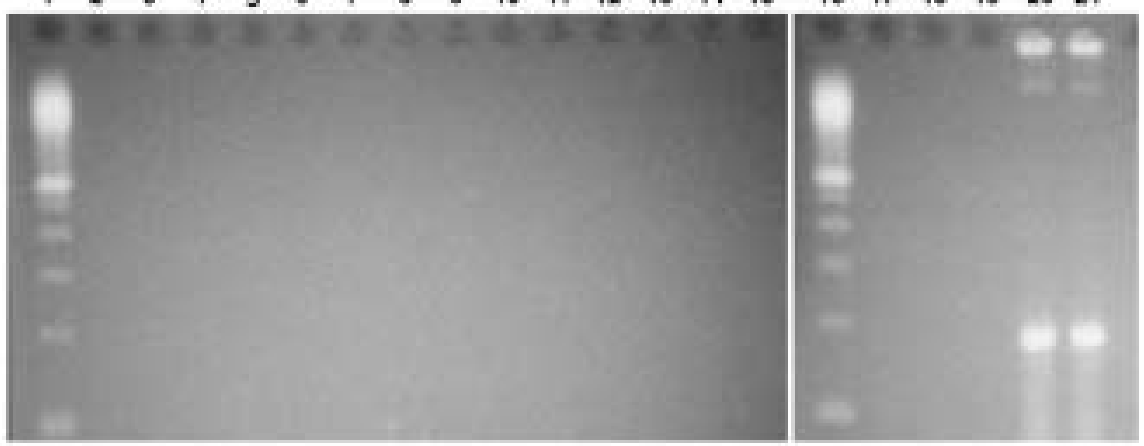

B

$\begin{array}{lllllllllllllllllllll}1 & 2 & 3 & 4 & 5 & 6 & 7 & 8 & 9 & 10 & 11 & 12 & 13 & 14 & 15 & 16 & 17 & 18 & 19 & 20 & 21\end{array}$

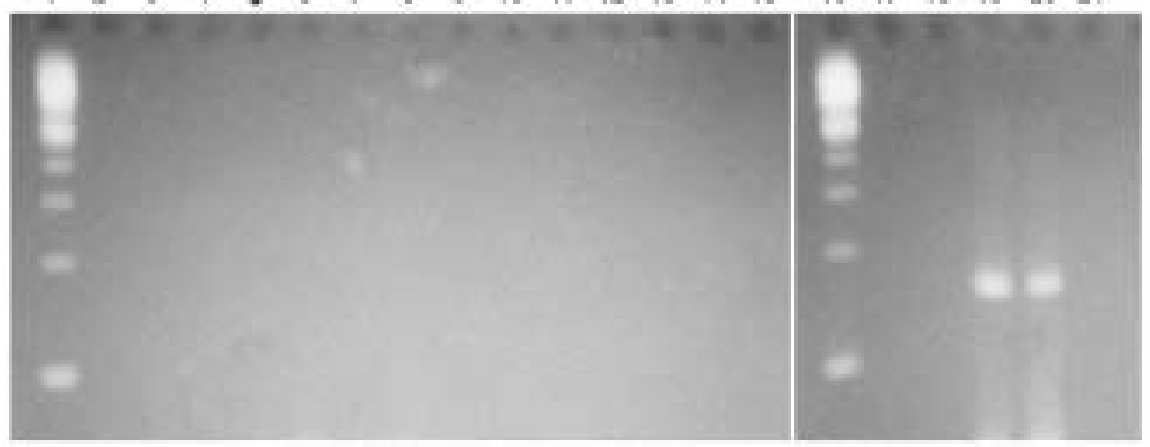

Figure 2 Results of real-time PCR were confirmed with agarose gel electrophoresis of PCR products. No amplification was observed for (A) GBS negative samples (A lanes 2-I5 and I7) or (B) $E$. coli negative samples (B lanes 2-I5 and 20-2I). Negative control (PCR water, AI8 and BI9) tested appropriately. Positive control and spiked sample for GBS (AI9-20) yielded the I53 bp amplification product whereas positive control and spiked sample for $E$. coli (BI7-18) yielded the 186 bp PCR product

compared with standard culture and traditional PCR. The overall time required to obtain results from real-time PCR was 7 h 40 min, including the incubation time. Testing was completed at a material cost of $\$ 8.50$ per amniotic fluid sample. We have also shown with sensitive and specific biomolecular techniques that the amniotic cavity under uncomplicated clinical conditions is sterile with respect to GBS and E. coli in the midtrimester.

If confirmed in future studies, the clinical implications of our data may lead to changes in diagnostic methods and clinical management of chorioamnionitis, preterm labor and pPROM. Future research should focus on validating this real-time PCR system in other clinical populations, including cases of suspected preterm labor,
pPROM or chorioamnionitis. We are currently planning such a study, to include patients with these diagnoses. We also plan to correlate PCR results with various adverse neonatal outcomes. With further study, it may become possible to more accurately and more rapidly identify earlier in gestation those pregnancies destined to deliver premature neonates that may develop sepsis. Early discovery of intra-amniotic infection may allow specific therapy in utero and maintainance of such pregnancies closer to term, as in the case of listeriosis. Conversely, early identification of intra-amniotic bacterial invasion may indicate expeditious delivery rather than ineffective maternal tocolytic or antibiotic therapy as the best strategy for reducing neonatal infectious morbidity and mortality. 

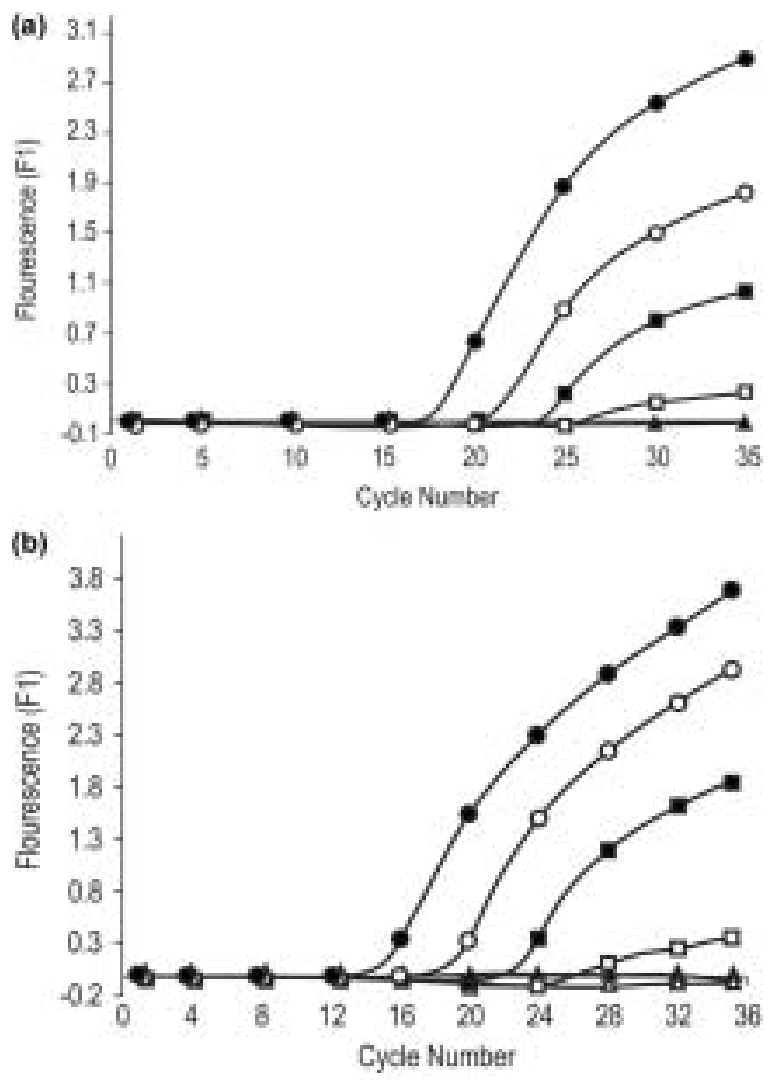

Figure 3 The limit of detection of the real-time Hybridization PCR assay for GBS and Taqman assay for $E$. coli were determined by serial dilution of extracted GBS or E. coli DNA before real-time PCR using LightCycler $^{T M}$. Each concentration was performed in triplicate and the average was used in the plot (solid circle, $10 \mathrm{ng} / \mathrm{rxn}$; open circle, I ng/rxn; solid square, $100 \mathrm{pg} / \mathrm{rxn}$; open square, $10 \mathrm{pg} / \mathrm{rxn}$; closed triangle, I pg/rxn)
In summary, the results of our study suggest that real-time PCR technology is a promising method that may improve diagnostic accuracy and rapidity in identifying intra-amniotic infection, and may open new windows for applying therapy to prevent preterm delivery and neonatal morbidity and mortality from prematurity. However, before this technique can be applied clinically, further research is necessary. The sensitivity and specificity of real-time PCR needs to be evaluated and validated in the most important clinical target population, namely women at 24 to 32 weeks of gestation who are at increased risk for preterm delivery or pPROM or are suspected to have preterm labor. In addition, probes for other common and uncommon pathogens need to be tested.

\section{Acknowledgement}

The views expressed in this material are those of the authors, and do not reflect the official policy or position of the U.S. Government, the Department of Defense, or the Department of the Air Force. The work reported herein was performed under United States Air Force Surgeon GeneralApproved Clinical Investigation.

\section{REFERENCES}

1. Andrews WW, Hauth JC, Goldenberg RL. Infection and preterm birth. Am J Perinatol 2000;17(7): 357-65

2. Romero R, Sirtori M, Oyarzun E, et al. Infection and labor. Prevalence, microbiology, and clinical significance of intraamniotic infection in women with preterm labor and intact membranes. $A m \mathrm{~J}$ Obstet Gynecol 1989;161(3):817-24
3. Oyarzun E, Yamamoto M, Kato S, et al. Specific detection of 16 microorganisms in amniotic fluid by polymerase chain reaction and its correlation with preterm delivery occurrence. Am J Obstet Gynecol 1998;179:1115-9

4. Romero R, Mazor M. Infection and preterm labor. Clin Obstet Gynecol 1988;31:553-84 
5. Hitti J, Riley DE, Krohn MA, et al. Broadspectrum bacterial rDNA polymerase chain reaction assay for detecting amniotic fluid infection among women in premature labor. Clin Infect Dis 1997; 177:1471-7

6. Markenson GR, Rodger K, Martin RK, et al. The use of polymerase chain reaction to detect bacteria in amniotic fluid in pregnancies complicated by preterm labor. Am J Obstet Gynecol 1997;177(6): 1471-7

7. Danbing KE, et al. Development of conventional and real-time PCR assays for the rapid detection of group B streptococci. Clin Chem 2000;46(3):32431
8. Gerber S, Vial Y, Hohlfel P, Witkin SS. Detection of Ureaplasm urealyticum in second-trimester amniotic fluid by polymerase chain reaction correlates with subsequent preterm labor and delivery. J Infect Dis 2003;187(3):518-21

9. Yoon BH, Romero R, Miha K, et al. Clinical implications of detection of Ureaplasma urealyticum in the amniotic cavity with polymerase chain reaction. Am J Obstet Gynecol 2000;183(5): $1130-7$ 


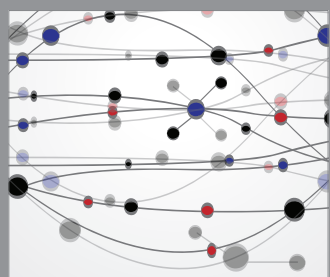

The Scientific World Journal
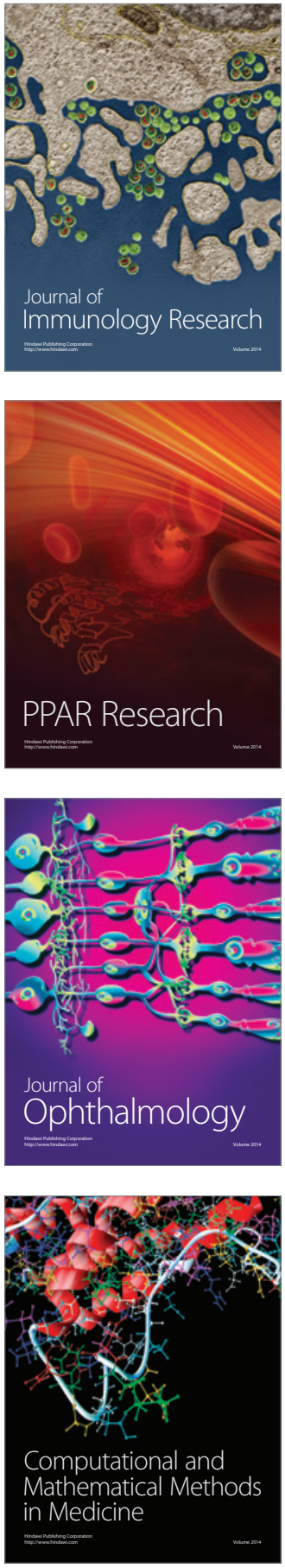

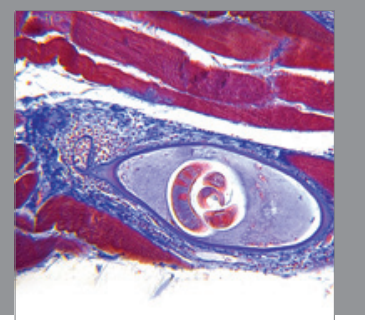

Gastroenterology

Research and Practice
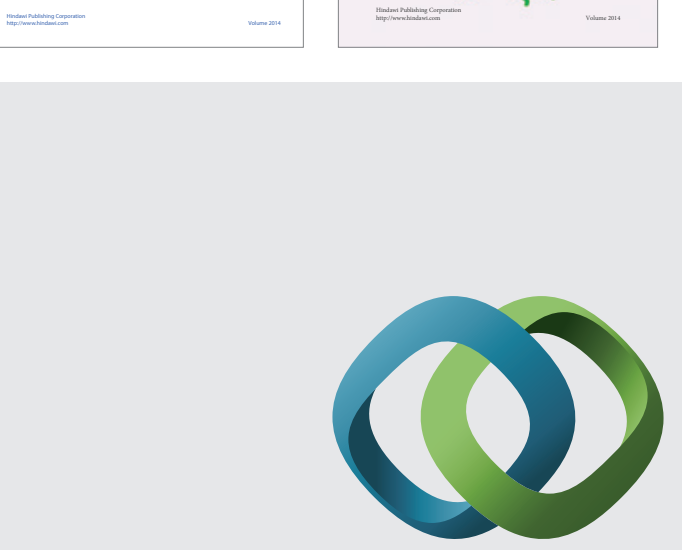

\section{Hindawi}

Submit your manuscripts at

http://www.hindawi.com
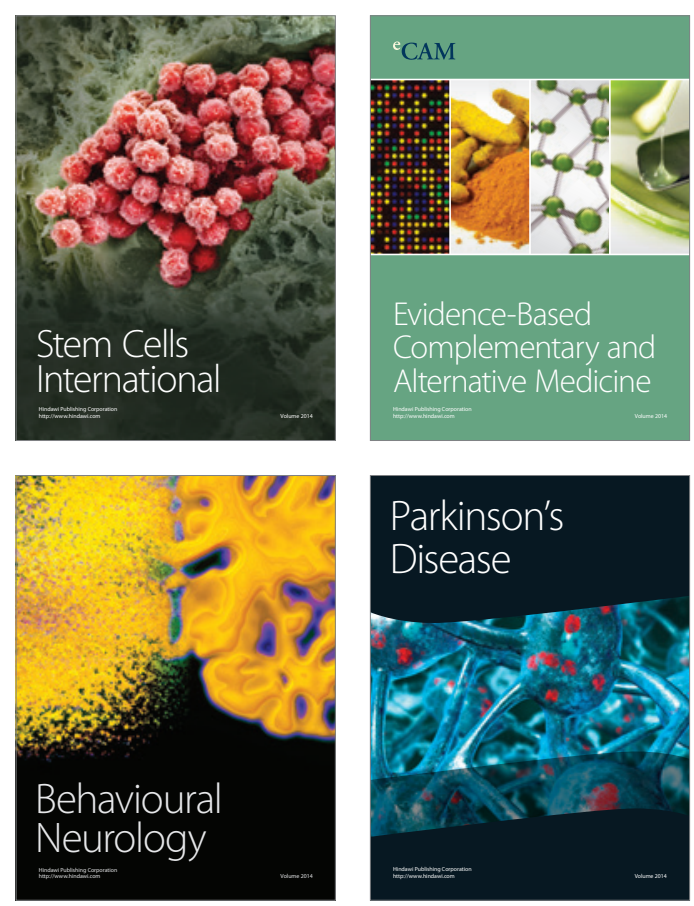

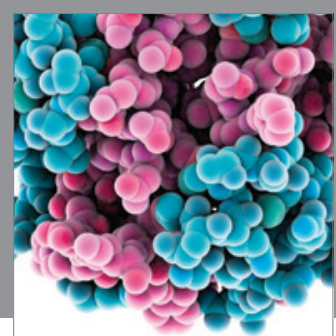

Journal of
Diabetes Research

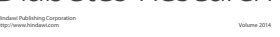

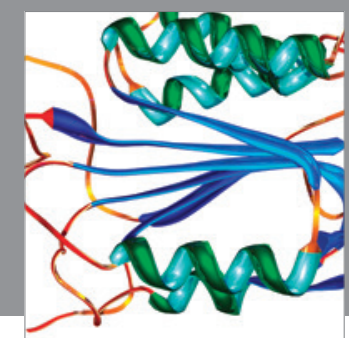

Disease Markers
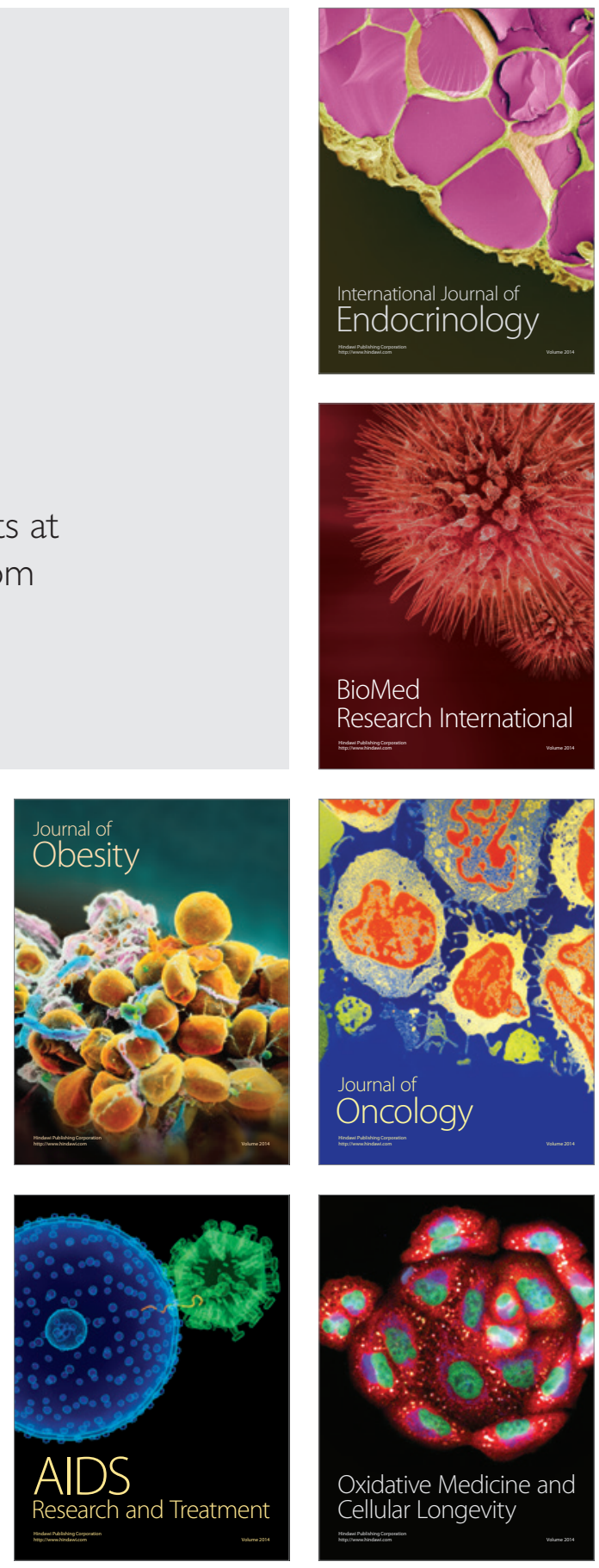